University of Nebraska - Lincoln

DigitalCommons@University of Nebraska - Lincoln

8-1996

\title{
The Poverty of Political Culture
}

Robert W. Jackman

University of California - Davis

Ross A. Miller

University of Nebraska - Lincoln, rmiller10@unl.edu

Follow this and additional works at: https://digitalcommons.unl.edu/poliscifacpub

Part of the Political Science Commons

Jackman, Robert W. and Miller, Ross A., "The Poverty of Political Culture" (1996). Faculty Publications: Political Science. 49.

https://digitalcommons.unl.edu/poliscifacpub/49

This Article is brought to you for free and open access by the Political Science, Department of at DigitalCommons@University of Nebraska - Lincoln. It has been accepted for inclusion in Faculty Publications: Political Science by an authorized administrator of DigitalCommons@University of Nebraska - Lincoln. 


\title{
The Poverty of Political Culture*
}

\author{
Robert W. Jackman, University of California, Davis \\ Ross A. Miller, Santa Clara University
}

The analyses reported by Granato, Inglehart, and Leblang (1996; hereafter GIL) are a major improvement over the studies that we examined in our paper. Especially notable is their explicit evaluation of the cultural explanation against a major rival, as represented by endogenous growth models of scholars like Barro (1991), Levine and Renelt (1992), and Helliwell (1994). These models regress economic growth rates over a given period on a set of initial economic, human capital, and other variables. It is in the context of such models that GIL report a significant, independent effect of culture on growth.

GIL's attention to the robustness of their estimates contrasts sharply with the studies evaluated in Jackman and Miller (1996). Their analysis departs from recent treatments in another way. In contrast to Inglehart (1990), for example, who examines the seven different components of culture that we discuss, GIL restrict their attention to just two: postmaterialism and achievement motivation. They find that only achievement motivation affects growth, which serves as the basis for their conclusion about the importance of culture. In this sense, their work stands as a key amendment to recent studies with their emphasis on norms of trust, satisfaction, participation, and the like and signals a return to earlier work, exemplified most notably by McClelland's studies of need for achievement (1961; 1963; McClelland and Winter 1969). Given the exclusion of the former norms from GIL's analysis, along with their reported nonresults for postmaterialism, we take it that they regard achievement motivation as the only "cultural" value affecting economic growth. This narrows the field a good deal. ${ }^{1}$

While there is thus much to recommend their paper over previous work, GIL's conclusion is ultimately unconvincing, on both theoretical and empirical grounds. We address these areas in turn.

\footnotetext{
*We would like to thank Donna Bahry, Bruce Bueno de Mesquita, Mary Jackman, Stephen Nicholson and Randolph Siverson for their helpful suggestions, and Duane Swank for sharing some of his data. We also acknowledge support from the Institute of Governmental Affairs and the Academic Senate, University of California, Davis.

${ }^{1}$ Recall (from our Table 6) that Inglehart (1990) does not discuss achievement motivation, but does address seven other measures of cultural values. Since six of these are not addressed by GIL, we take it that they are not now seen as factors that might influence economic growth. Recall further (from our Table 6) that our own analysis indicated that postmaterialism, 1980, did not influence economic growth, 1980-88.
}

American Journal of Political Science, Vol. 40, No. 3, August 1996, Pp. 697-716

(C) 1996 by the Board of Regents of the University of Wisconsin System 


\section{Theoretical Issues}

GIL's theoretical discussion hinges on a ritual invocation of Weber's (1958) argument about Protestantism, an argument that is central to the cultural account (Jackman and Miller 1996; Fukuyama 1995, esp. chap. 5). ${ }^{2}$ Among other things, GIL claim that:

The cultures of virtually all preindustrial societies are hostile to social mobility and individual economic accumulation. Thus, both medieval Christianity and traditional Confucianism stigmatized profit-making and entrepreneurship.... Preindustrial economies are zero-sum systems: they are characterized by little or no economic growth. ... Weber's emphasis on the role of Protestantism seems to capture an important part of reality. The Protestant Reformation combined with the emergence of scientific logic broke the grip of the medieval Christian worldview on a significant part of Europe (1996, 608-10).

Their essential story is thus as follows: Europe was economically stagnant throughout the Middle Ages and would have remained so, had it not been for the exogenous shock induced by the Reformation generally, and by Calvinism in particular. Absent that exogenous shock, economic activity in Europe could not have moved from one equilibrium (stagnation) to another (growth).

This portrait is, however, inconsistent in every crucial respect with the record accumulated by historians since at least 1945. Summarizing radically, there is evidence of considerable technological change, some indigenous and some borrowed from Asia, during the Middle Ages (i.e., the period from AD 500 to AD 1500). This innovation was of sufficient magnitude to lead Gies and Gies (1994) to conclude that the Europe of 1500 would have been unrecognizable to those who had lived at the beginning of the millennium.

Second, there was a sustained pattern of economic growth during the Middle Ages, one that involved a general expansion of commerce, trading and banking, and a pattern in which the pre-Reformation Church participated. Accompanied by population growth, this economic expansion may not have raised living standards from "high to higher," but the shift "from very low to less low" was nonetheless both sustained and remarkable (Reynolds 1961, 156).

\footnotetext{
${ }^{2}$ For good measure, they also invoke Tawney (1926). This bracketing of Tawney and Weber is odd, however, given that Tawney argued (contrary to Weber) that religious activity was inherently inimical to economic growth. Thus, Tawney's explanation of economic growth after the Reformation emphasized the erosion of religious authority generally, not the emergence of doctrinal modifications associated with Calvinism or any other particular theology.
} 
Third, the record indicates that Protestantism generally (especially Calvinism) did not place an unambiguous and overriding weight on achievement norms. It is indeed difficult even to sustain a clear contrast between Calvinism, Lutheranism, and Catholicism in the importance that each attached to achievement norms. Thus, it is unclear how Protestantism (or Calvinism) could even plausibly have been a principal stimulus that generated capitalism.

Fourth, there was an exogenous shock that affected patterns of economic growth, but this came as the Black Death (or Plague) and associated events, during which it is estimated that Europe lost at least one-third of its population, and after which land and grain prices plunged. Further, the Black Death occurred in the late Middle Ages (in the mid-fourteenth century), predating the changes with the Reformation that concerned Weber. ${ }^{3}$

Weber's empirical analysis, however, started with the fifteenth century. Not recognizing this as the tail of a trough in economic activity, he instead extrapolated back to the twelfth and thirteenth centuries, on the erroneous assumption that they must have been "even more rudimentary and primitive" than the fifteenth (Gilchrist 1969, 126). Had he understood the fifteenth century as the end of a trough, it might have become clear that the "new" forms of capitalist activity he attributed to Calvinist theology were in fact much less novel than they otherwise appeared. Weber's historical analysis thus suffers from the selection bias associated with censored time series (Geddes 1990), the censoring in this instance occurring at the beginning of the series. Once this is recognized, the basis for GIL's initial premise evaporates: their historical claims summarized above are inaccurate in every key respect, as is their conclusion that "Weber is correct in arguing that the rise of Protestantism is a crucial event in modernizing Europe" $(1996,609)$.

\section{Empirical Issues}

GIL's dependent variable covers the years from 1960 through 1989 , following Levine and Renelt (1992). Their data on initial GDP and on primary and secondary school enrollment ratios are for 1960 ("the beginning

${ }^{3}$ There is, of course, a voluminous literature that addresses these issues, the cumulative implications of which undermine the empirical basis for Weber's historical thesis. The above discussion draws on Barrow (1990), Bossy (1985), Bridbury (1992), Britnell (1993a, 1993b), Britnell and Campbell (1995), Carus-Wilson (1967), Cipolla (1980), Cohen (1980), Day (1987), de Roover (1963, 1974), Epstein (1991), Gilchrist (1969), Gies and Gies (1972, 1994), Hatcher (1986, 1994), Hunt (1994), Lehmann and Roth (1993), Lopez (1976), MacKinnon (1988, 1994), McNeill (1977), Miller and Hatcher (1995), Outhwaite (1986), Persson (1988), Reynolds (1961), Samuelsson (1961), Titow (1994), Trevor-Roper (1972, esp. chap. 1), White (1978), and Wright (1982) 
of the time period," as GIL properly emphasize), while their data on investment rates are averaged over the years from 1960 through 89 . In stark contrast, data for the two measured components of cultural values are drawn from the World Values Survey for 1990. That these variables are measured for 1990 may not be obvious since it is reported only in the notes to GIL's Appendix Table 1. The subject is not broached elsewhere in the text and hence may escape those readers who make the usually plausible assumption that all the explanatory variables temporally predate the dependent variable. $^{4}$

Perhaps labelling Culture ${ }_{1990}$ as a "significant predictor" of Growth $_{1960-89}$ (as do GIL) is less awkward than we believe. Indeed, were there evidence that the values at hand are largely time-invariant, the use of Culture ${ }_{1990}$ as an approximate proxy for Culture ${ }_{1960}$ might be warranted. The evidence in Jackman and Miller (1996) indicates, however, that these values can vary substantially over time, as a function of both long- and short-term patterns (see also Clarke and Dutt 1991; Clarke, Dutt, and Kornberg 1993; Duch and Taylor 1993; Abramson and Inglehart 1995). GIL themselves emphasize that "central elements of culture can and do change.' If so, Culture ${ }_{1990}$ is an inadequate proxy for Culture ${ }_{1960}$, and GIL's empirical analysis is simply indefensible. A trait measured at time ${ }_{t}$ cannot be used to explain an "outcome" measured at time ${ }_{t-1}$.

At the same time, there is another way to evaluate GIL's argument. McClelland $(1961,90)$ provided data on national levels of need for achievement collected for 1950 . These data are based on codings of themes emphasized in textbooks read by children from second- through fourth-grade levels, and are fully discussed by McClelland (1961, chap. 3). The 1950 date for these figures is almost ideal for our purposes, as the children exposed to these readers circa 1950 would be adults and at least potential labor force members by 1960 , and they would play an increasingly important role in economic patterns over the ensuing years, 1960-89. McClelland's 1950 data are available for 19 of the 25 countries examined by GIL. ${ }^{5}$

${ }^{4}$ A series of World Values Surveys were also carried out between 1981 and 1983, but this earlier series did not include seven of the 25 countries analyzed by GIL (Abramson and Inglehart 1995, 97-9). The seven countries not surveyed in 1981-83 are Austria, Brazil, China, India, Nigeria, Switzerland, and Turkey.

${ }^{5} \mathrm{McClelland}$ also reported need for achievement estimates for 1925. In fact, he was especially attentive to issues of temporal ordering. Consider the following:

The estimates of $n$ Achievement [1925] are positively correlated with subsequent economic growth and very significantly so. . . . On the other hand, $n$ Achievement level as estimated from the 1950 readers is not related to previous economic growth. The difference in the two sets of correlations is particularly important theoretically because it bears on the issue of economic determinism. ... Marx appears to have been somewhat premature in dismissing psychology as a major determinant in history (McClelland 
Table 1. Regressions of Economic Growth on Initial GDP, School Enrollment Ratios, Investment, and Need for Achievement Levels, 1950 [Coefficients (t-ratios); $N=19$ ]

\begin{tabular}{lccc}
\hline \hline & OLS & $\begin{array}{c}\text { Robust } \\
\text { Regression }\end{array}$ & $\begin{array}{c}\text { Median } \\
\text { Regression }\end{array}$ \\
\hline GDP per capita, 1960 & -.35 & -.38 & -.32 \\
Primary education, 1960 & $(3.1)$ & $(4.8)$ & $(5.4)$ \\
& 1.66 & 1.22 & 1.03 \\
Secondary education, 1960 & $(1.6)$ & $(1.7)$ & $(1.6)$ \\
& 2.57 & 2.29 & 2.16 \\
Investment, 1960-89 & $(3.5)$ & $(4.4)$ & $(5.4)$ \\
& 9.49 & 10.85 & 10.13 \\
Need for achievement, 1950 & $(2.7)$ & $(4.3)$ & $(5.9)$ \\
& -.06 & -.06 & -.07 \\
Constant & $(0.2)$ & $(0.3)$ & $(0.5)$ \\
& -.65 & -.24 & -.09 \\
$R^{2}$ & $(0.5)$ & $(0.3)$ & $(0.2)$ \\
$F$-ratio & .61 & $\mathrm{n} / \mathrm{a}$ & .55 \\
\hline
\end{tabular}

Data are from Granato, Inglehart, and Leblang (1996, Appendix Table 1), and from McClelland $(1961,90)$. All calculations are made with the STATA statistical package.

Accordingly, Table 1 displays the estimates obtained when economic growth rates, 1960-89, are regressed on GDP per capita and school enrollment ratios, 1960, domestic investment, 1960-89, and McClelland's measure of need for achievement, 1950. The first column shows the OLS estimates, while two alternative robust sets of estimates are shown in the remaining columns. These estimates employ GIL's data, and the regression model closely matches their Table 1 , model 3 , except that the $\mathrm{N}$ is 19 rather than 25 .

Comparing across columns, it is evident that the estimates are quite robust, in the sense that they are similar across the different estimating procedures. Second, the core endogenous growth model performs well, even with the reduced number of cases. Only the coefficient estimates for primary school enrollments are of borderline statistical significance, with t-ratios just above 1.5 (note that they remain correctly-signed). Third, and most important, there is no evidence here of a need for achievement effect:

1961, 93, italics in original).

Even so, his conclusions are difficult to sustain in light of analyses like Barro (1991) and Levine and Renelt (1992). Among other things, McClelland relied heavily on zero-order correlations. 
the relevant coefficient estimates are incorrectly signed and the t-ratios hover below 0.5 . In other words, when achievement motivation is analyzed on the basis of a defensible temporal ordering of the measured variables, there is no evidence that it influences economic growth one way or the other.

Given this noneffect, how can we account for the connection between growth, 1960-89, and values, 1990, described by GIL? This question is best addressed in terms of the alternative perspective sketched in Jackman and Miller (1996) that draws on analyses like Hirschman (1984) and Gambetta (1993) that endogenize values. Recall that in GIL's analysis, achievement motivation is gauged from a question asking respondents to rank "qualities which children can be encouraged to learn at home." It is said to increase directly with the proportion stressing " thrift, saving money and things," and "determination," while it also increases inversely with the proportion emphasizing the traditional social values of "obedience" and "religious faith."

Our hypotheses are straightforward. First, economic growth generates higher levels of achievement motivation, thus defined, because it creates a climate where norms favoring saving and "determination" make sense. In contrast, saving is often suboptimal (and indeed there are fewer incentives for saving) in periods of poor economic performance with their typically higher rates of inflation and unemployment. ${ }^{6}$ Second, investment in human capital generates higher levels of such achievement motivation insofar as it fosters the diffusion of achievement-oriented norms and undermines more "traditional" social values. We anticipate this effect to be most pronounced with investment in secondary (as opposed to primary) education, the clientele for which is closer to adulthood and thus closer to entering the labor force.

These two hypotheses are readily evaluated using the data reported by GIL in their Appendix Table 1. Table 2 displays estimates obtained when achievement motivations, 1990, are regressed on economic growth rates, 1960-89, and school enrollment ratios, 1960. The OLS estimates in the first column of the table are consistent with both hypotheses. Economic growth has the most pronounced positive effect, and has a t-ratio considerably greater than 2.0. Both of the estimates for school enrollment ratios are positive, except that the primary school enrollment coefficient is smaller than its standard error. The t-ratio for the secondary enrollment coefficient is greater than 2.0, and the estimated coefficient itself is four times the size of that for primary enrollment (these two right-hand variables share a

${ }^{6} \mathrm{GIL}$ recognize the "possibility that economic growth might be conducive to thrift," but assert that the rationale for such an argument is "less obvious." The assertion is puzzling. 
Table 2. Regressions of Need for Achievement, 1990, on Prior Economic Growth and Initial School Enrollment Ratios [Coefficients (t-ratios); $N=25$ ]

\begin{tabular}{lccc}
\hline & OLS & $\begin{array}{c}\text { Robust } \\
\text { Regression }\end{array}$ & $\begin{array}{c}\text { Median } \\
\text { Regression }\end{array}$ \\
\hline Economic growth, 1960-89 & .22 & .19 & .17 \\
Primary education, 1960 & $(4.8)$ & $(3.6)$ & $(3.6)$ \\
& .20 & .21 & .15 \\
Secondary education, 1960 & $(0.7)$ & $(0.6)$ & $(0.5)$ \\
& .81 & .88 & .95 \\
Constant & $(2.9)$ & $(2.6)$ & $(2.7)$ \\
& -1.16 & -1.14 & -1.08 \\
$R^{2}$ & $(4.2)$ & $(3.4)$ & $(3.4)$ \\
$F$-ratio & .69 & $\mathrm{n} / \mathrm{a}$ & .44 \\
\hline
\end{tabular}

Data are from Granato, Inglehart, and Leblang (1996, Appendix Table 1).

common metric). Overall, this simple model fits the data quite well (the adjusted $R^{2}$ is .64 and the SEE is .28). Columns three and four of the table display robust estimates for the model, and show that the parameter estimates are relatively stable across different estimators.

Before we embrace the proposition that "achievement norms" are the phenomenon generated by the explanatory variables in Table 2 , however, one remaining empirical issue warrants clarification. The measure employed by GIL is generated from aggregate responses to only four of the 11 items listed in the Appendix below. Specifically, GIL (a) sum the percentage of respondents in each country emphasizing the virtues of "thrift, saving money and things" and "determination," (b) sum the percentage of respondents stressing "obedience" and "religious faith," and then subtract (b) from (a). The implicit assumption here, of course, is that these four items constitute a single coherent cluster of attitudes across and within countries, so that a high country score indicates that there are many individuals who attach a high value to thrift and determination and who simultaneously place much less weight on obedience and religious faith, etc. How reasonable is this assumption?

The first column of Table 3 displays the loadings from a principal components analysis of the four measures of achievement motivation for the 25 cases examined by GIL. These estimates provide some apparent evidence for a relatively coherent cluster of attitudes, as the first factor has an eigenvalue of 2.48 , and no additional factors with eigenvalues greater than 1.0 are extracted. The loadings for the first two measures (thrift and 


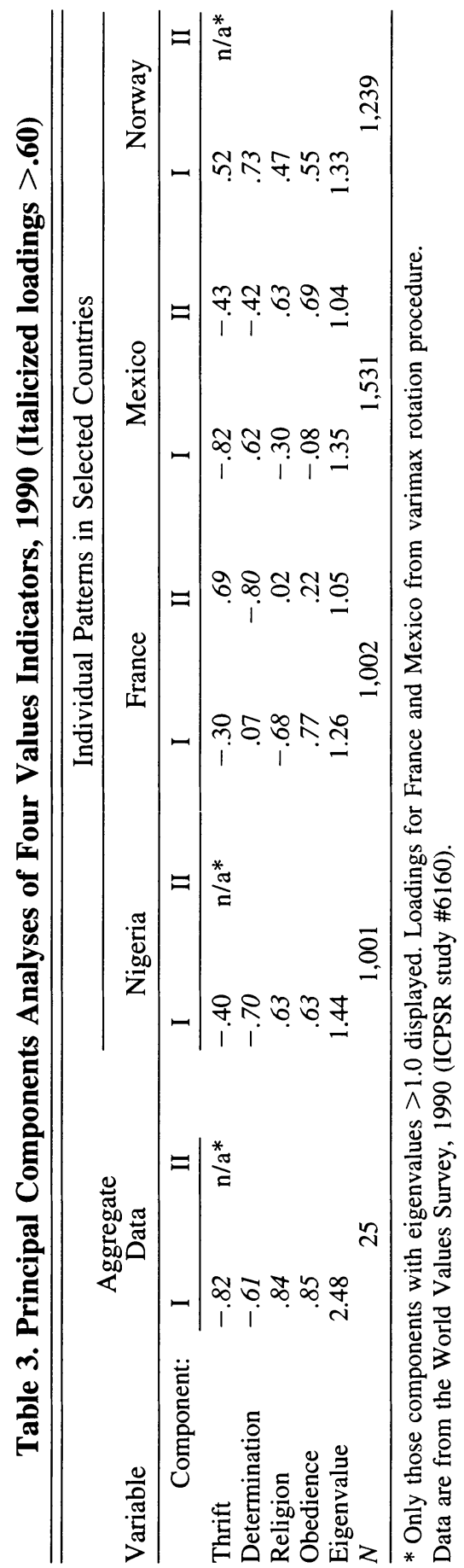


determination) have the same sign (negative) and are relatively strong ( -.82 and -.61 , respectively). The loadings for the third and fourth measures (religion and obedience) are also in the expected direction (positive) and quite high (.84 and .85 , in turn). The substantive interpretation of the factor in the first column appears consistent, moreover, with GIL's argument: a country with a high factor score is one where citizens attach less importance to thrift and determination and place more weight on religion and obedience.

Unfortunately, we find very little evidence of comparable patterns within these same 25 countries. In fact, in only three cases (India, Nigeria, and South Africa) do we find the same pattern. To illustrate, the estimates for Nigeria are shown in the second column, and suggest a single-factor solution. While the loadings are weaker than those found in the aggregate analysis (not surprisingly, given that these involve individual-level data), the four items do cluster similarly in the Nigerian and aggregate analyses.

For 22 of the 25 countries, however, there is no such structure across the four items, and in fully 17 of these 25 cases, a two-factor solution is warranted (i.e., there are two components with eigenvalues $>1.0$ ). The remaining three columns in Table 3 illustrate the diversity of factor solutions. In both France and Mexico, for example, we obtain a two-factor solution, where thrift and determination cluster into one factor and religion and obedience cluster into another, and where the loadings for thrift and determination are of opposite signs! For Norway, in contrast, we do estimate a single-factor solution: however, the loadings are incorrectly-signed (given GIL's argument), and only one exceeds .60. At the individual level, then, these four items fail to cluster into the single coherent dimension anticipated by GIL for almost all of the cases that they consider.

Finally, recall that the four items examined in Table 3 are a subset of the 11 items listed in our Appendix. The principles guiding GIL's selection of this subset are, however, unclear. Why, for example, is "determination and perseverance" included as part of the achievement syndrome when "hard work" and "feeling of responsibility" are not? To save space, we do not display the estimates here, but a component analysis of all 11 (aggregated) items across all 25 cases generates three factors. Further, the rotated (varimax) loadings have "hard work" on the second component (along with "imagination" and "tolerance"), and thus counterintuitively treat "hard work" as distinct from "determination." The corresponding component analyses of all 11 items within each of the 25 countries generate a considerable miscellany of solutions, few of which are amenable to a clear substantive interpretation.

We emphasize in Jackman and Miller (1996) that the core of the political culture account addresses the prevalence of value clusters within coun- 
tries, clusters that assume political and social meaning insofar as they are widely shared across individuals. There is no evidence of any such coherent clustering in GIL's data to warrant either their narrower claims about achievement motivation or their broader claims about political culture.

\section{Summary}

GIL's argument that culture drives economic growth is unconvincing. First, like most such claims, it is predicated on Weber's explication of a role for Protestantism in economic growth, one belied by the historical evidence. Second, GIL's empirical analyses are fatally flawed. Specifically,

(a) the measure of their principal explanatory variable constitutes an ex post "predictor;"

(b) an ex ante measure of achievement motivation has no systematic effect on subsequent economic growth;

(c) evidence suggests that their measure of culture is more profitably cast as an outcome of economic growth; and

(d) the meaning of that measure of culture is obscure (GIL to the contrary, it certainly cannot be interpreted as a unidimensional gauge of achievement motivations).

\section{Swank's Commentary}

Remarkably, Swank does not address any of the theoretical or empirical issues discussed above. ${ }^{7}$ While the bulk of his comments concern culture and economic growth, Swank addresses our reanalysis of Putnam (1993) in only two paragraphs, and his brief discussion distorts what we say. For example, Swank notwithstanding, we do not "suggest through principal components analysis at least four dimensions of [institutional] performance" (1996, 666). Instead, we employ the identical data and estimating procedures as Putnam to demonstrate that he confuses assumptions with conclusions, and that absent his strong assumptions there is no basis for

\footnotetext{
${ }^{7}$ To be sure, Swank does acknowledge that the dating of GIL's measure of need for achievement may be an issue. This acknowledgement comes only in his footnote 4 , however, and Swank obviously fails to recognize the gravity of the problem. Thus, he proceeds as if GIL's dating of their key independent variable were not an issue (as in the first two columns of his Table 1 and the surrounding discussion). Further, Swank to the contrary, neither our discussion nor GIL's "suggests that this variable [need for achievement] will be somewhat stable overtime" (Swank 1996, footnote 4).
} 
those conclusions. ${ }^{8}$ The point is simple, fundamental, and inescapable. Putnam's analysis fails on its own terms. ${ }^{9}$

Most of Swank's commentary centers on the impact on growth of "communitarian politics." Ignoring his own admonition to avoid "singleequation, linear models of what theoretically is a multifaceted, complex relationship" (665), Swank proceeds to estimate such models in which communitarianism is represented by "corporatism" and "Confucianism." We briefly discuss these in turn.

\section{Corporatism}

Swank is selective in his discussion of social corporatism, and creates the false impression that there is a measure of agreement about linkages between corporatism and economic growth. Thus, he cites Lange and Garrett (1985) to this effect, but ignores the criticism in Jackman (1987). Similarly, he mentions Hicks, who declared that with the addition of "several key control variables" the Lange-Garrett model is "robust" (Hicks 1988, 677), but ignores the fact that Hick's model is overfitted and has meager degrees of freedom (Jackman 1989). Problems of robustness also plague the claims about corporatism advanced in Swank (1992), as shown by Beck and Katz (1995), but Swank cites only the former source.

In addition to this selectivity, Swank's measure of corporatism is weak. While he opines that culture is "multifaceted," he actually relies on a simple dummy variable to reflect the presence of communitarian values. This is too blunt an instrument to measure adequately the "clusters of values, attitudes, and norms that support, and are reinforced if not facilitated by,

${ }^{8}$ Thus, our purpose has been to show that Putnam's own data do not warrant the conclusions he draws. We do not mean to suggest, however, that this is the only basis for criticism of his inferences. For example, Putnam traces regional differences in governance during the 1980s back to patterns of civic engagement at the end of the last century, and often to much earlier civic traits. One reasonably wonders how he would have proceeded had he been investigating regional differences in governance during the Mussolini period, i.e., the 1930s. What patterns of civic (dis)engagement would these have reflected, and when exactly would those patterns have been manifested?

${ }^{9}$ Swank's comments about specification are completely extraneous. In our reanalysis, we include Putnam's indicator of economic development. This comes from a principal components analysis of six elements: net income per capita, 1972; gross domestic product per capita, 1970; the size, respectively, of the agricultural and industrial workforces, 1977; and the value added share, respectively, for agriculture and industry 1979. In light of the endogenous growth and related empirical models such as those we have discussed, it is evident that each of these elements provides evidence on patterns of physical capital and investment within Italy's regions. 
institutions, policies and practices," all part of a complex whole that Swank claims constitute a core explanatory variable $(1996,667)$.

Finally, Swank provides no evidence beyond a vague reference to the "extant literature" $(1996,672)$ to support his classification for fully half of the noncorporatist states (his Appendix shows missing data for 10 of these 20 cases). Given this lack of evidence, coupled with the crudeness of Swank's index of social corporatism, one wonders how he developed his classification.

\section{Confucianism}

We noted in Jackman and Miller (1996) the tendency toward ex post explanation in the cultural account. In his evaluation of a related cultural interpretation of development, Billig clearly states the problem:

The view of culture expressed by the new cultural determinists tends to be the static, synchronic version beyond which anthropology has largely progressed. ... Note how the logic works: these words - authoritarian, individualistic, present-time-focused, etc.-characterize this thing called Hispanic American culture and lead inexorably to maladaptive types of economic activity. These values and attitudes exist in the shared consciousness of Hispanic Americans and result in a business ethos that obstructs the type of enterprise we see in more successful countries, presumably ones that have prior cultural traits that foster a better kind of economic activity. Since we have only recently become aware of what constitutes good kinds of activity, it must be the case that those societies whose cultures encouraged that kind were pretty lucky; the others, well, let us hope their cultures are flexible enough to get with the program (1994, 661, italics in original).

And so it is with Confucianism. Weber, of course, went to great lengths to distinguish Puritanism from Confucianism: "Confucian rationalism meant rational adjustment to the world; Puritan rationalism meant rational mastery of the world" (1951, 248). Indeed, to provide further substantiation of his argument in The Protestant Ethic, he devoted the entire last chapter of The Religion of China to the contrast between the two world views. The theme is echoed in more recent treatments. Thus, according to Pye:

The Confucian ideal was eminently appropriate for an agrarian society but was detrimental to the development of commerce and industry. Eventually the Confucian tradition of distrust for all that might unsettle the agricultural order worked against the Chinese in their confrontation with the modern industrial and technologically oriented West $(1991,34)$. 
A major difficulty with this description is that it squares poorly with the recent economic performance of many East Asian economies. There are, of course, different ways of resolving the dissonance thus introduced. One might, for example, conclude that there is no causal link between values and economic growth. Another tack, perhaps more consistent with Festinger (1957), involves an about-face on the content of Confucianism to render the latter consistent with the pattern of economic growth already observed. Such is the strategy proposed by pundits like Kahn and endorsed most recently by Swank:

Most readers ... are familiar with the argument of Max Weber that the Protestant ethic was extremely useful in promoting the rise and spread of modernization. Most readers, however, will be much less familiar with the notion that has gradually emerged in the last two decades that societies based upon the Confucian ethic may in many ways be superior to the West in the pursuit of industrialization, affluence, and modernization (Kahn 1979, 121, italics ours).

The "thing" labelled Confucianism is now refurbished as a pro-growth value system, and the basis for the East Asian economic "miracle" is thus revealed. The ex post reasoning here is glaring.

\section{Swank's Empirical Analyses}

There remains Swank's "theoretically driven empirical model," which he claims "does surprisingly well in explaining cross-national variations in economic growth rates and is robust in the face of alternative controls and statistical evaluations" $(1996,675)$. What can we learn from this model?

Table 4 displays four sets of OLS estimates. The figures in column (1) contain the estimates for the baseline model of economic growth with which GIL began their analysis. Column (2) shows the estimates obtained when the two dummy variables for Corporatism and Confucianism proposed by Swank are added to the model, and are similar to those he reports in his Table 1, column (3), except that they include insignificant parameter estimates for secondary enrollment ratios and investments. Comparing the two columns, we see that the coefficients for the two dummy variables are statistically significant beyond the .10 level (two-tailed test), and that their addition to the model improves its fit substantially (for example, the $\mathrm{R}^{2}$ increases from .63 to .87). This would appear strongly consistent with Swank's conclusions.

Recall that Swank's claim is that both Corporatism and Confucianism have separate, additive effects on growth. As is shown in column (3) of Table 4, however, we find no evidence of a corporatism effect on growth 
Table 4. OLS Regressions of Economic Growth on Initial GDP, School Enrollment Ratios, Investment, and Other Sundry Characteristics [Coefficients (t-ratios); $N=25$ ]

\begin{tabular}{lcccc}
\hline \hline & $(1)$ & $(2)$ & $(3)$ & $(4)$ \\
\hline GDP per capita, 1960 & -.63 & -.30 & -.61 & -.29 \\
& $(4.3)$ & $(2.7)$ & $(3.8)$ & $(3.3)$ \\
Primary education, 1960 & 2.69 & 3.30 & 2.43 & 1.64 \\
& $(2.1)$ & $(3.9)$ & $(1.8)$ & $(2.0)$ \\
Secondary education, 1960 & 3.25 & .32 & 3.38 & .45 \\
& $(3.2)$ & $(0.4)$ & $(3.2)$ & $(0.7)$ \\
Investment, 1960-89 & 8.12 & -1.41 & 10.13 & 2.53 \\
& $(1.8)$ & $(0.3)$ & $(1.8)$ & $(0.8)$ \\
"Corporatism" & & .69 & -.26 & .34 \\
& & $(1.8)$ & $(0.5)$ & $(1.1)$ \\
"Confucianism" & & 2.98 & & 2.39 \\
& & $(5.7)$ & & $(5.4)$ \\
"Failed Protestant colonies" & & & & -1.34 \\
& & .72 & -.84 & $(3.5)$ \\
Constant & $(0.7)$ & $(0.7)$ & $(0.7)$ & $(2.3)$ \\
& .63 & .87 & .64 & .92 \\
$R^{2}$ & 8.58 & 20.10 & 6.64 & 29.76 \\
$F$-ratio & & & & \\
\end{tabular}

Data from Granato, Inglehart, and Leblang (1996, Appendix Table 1), and from Swank (1996).

when the coefficient for Confucianism is constrained to zero: indeed, the applicable estimate is incorrectly signed and smaller than its standard error. A similar set of estimates is obtained when the set of Confucian economies is excluded from the analysis and the model in column (3) reestimated (figures not shown). Swank's estimates thus appear to be less robust than he believes, and a comparison of columns (2) and (3) in Table 4 suggests that "Confucianism" is the deus ex machina of his analysis.

Further perspective on the issue comes from an additional variable. As Swank observes, the 25 economies under consideration encompass some non-Western economies. Among these are three former British colonies, within which there were considerable Protestant missionary efforts during the nineteenth and early twentieth centuries. ${ }^{10}$ Such efforts were ultimately unsuccessful, however, as most people in these colonies did not convert,

${ }^{10}$ The literature on these activities is extensive. See, e.g., Ajayi (1965), Du Plessis (1911), Duvall (1928), Messmore (1903), Mitchell (1899), Ross (1986), and Stewart (1899). 
thereby rejecting the entrepreneurial values highlighted by Weber. We would on the average thus expect lower growth rates in these economies.

Column (4) of Table 4 reports the OLS estimates for a model containing a dummy variable that identifies these "failed Protestant colonies." Comparing these figures with those in column (2) shows that "Confucianism" still exerts a marked effect while the coefficient for "failed Protestant colonies" is also correctly signed with a t-ratio of 3.5. The fit for the model as a whole increases from .87 to .92 , a statistically significant improvement. Following the logic of Swank's analysis, we might therefore conclude that both factors are important to a complete explanation of economic growth.

Caution is in order, however. It is true that the three countries identified by Swank (China, Japan, and South Korea) are often labelled "Confucian," even though in religious terms Japan and Korea are not predominantly Confucian (e.g., Pye 1985). It is also true that the Protestant missions generally failed in the three countries we have identified (India, Nigeria, and South Africa), although Christianity in a more general sense has been successful in South Africa. ${ }^{11}$ These two binary variables are linked, however, in a more fundamental manner. The so-called "Confucianism" dummy actually identifies the three cases with the three highest scores on the dependent variable, namely, economic growth, 1960-89. Conversely, the dummy variable we have labelled "failed Protestant colonies" actually designates the three cases with the lowest rates of economic growth. These two "explanatory" variables are thus simply recoded versions of the dependent variable.

Swank's analysis brings new meaning to the problem of selecting on extreme values of the dependent variable. The difficulty with selecting observations for analysis on the basis of such values is well-known (e.g., Geddes 1990). Here, we are asked to go the next step. Identify a subset of such cases and give this subset a name (any name will do). Create a binary variable that equals one for cases in this subset, and zero otherwise, and include it on the right as an explanatory variable. Results are guaranteed, and indeed it is not surprising that "Confucianism" drives Swank's empirical analysis. Whether or not these "Confucian" economies comprise the Elect in a Calvinist sense, then, they certainly are the Select.

Our addition of a parameter for "failed Protestant colonies" (for want of a shorter term) serves simply to round out Swank's analysis and further improve the fit by taking care of those cases with low scores on the dependent variable. Under no circumstances, of course, do such efforts constitute

\footnotetext{
"The three countries we have identified are unusual in another sense: they are the only three cases for which the components of need for achievement used by GIL cluster together in the manner anticipated by GIL, as we indicated above (705).
} 
an explanation: economic growth is not usefully explained by itself. Instead, Swank's analysis simply perpetuates the ex post tendencies typical of so many cultural accounts, and carries them to their inescapable conclusion.

\section{Conclusion}

In light of our evaluation of Inglehart (1990) and Putnam (1993) we argued that "further attempts to refine and test the case for political culture along the lines we have addressed seem unlikely to be productive"' (Jackman and Miller 1996, 654). As we have shown here, neither GIL's nor Swank's analyses offer any material evidence to the contrary. Instead, they serve solely to underscore our original conclusion.

The most prominent problem with these analyses (one they share with many such analyses) is that they are ex post. This is an obvious issue with Swank's invocation of Confucianism as a growth-enhancing value (GIL also broach the question). Since he wishes to attribute the high rates of growth observed in the East Asian Newly-Industrializing Countries (NICs) to values, Swank summons a common "Confucian" culture as the explanation. While it is a little more masked, the same predicament plagues GIL's inquiry. It is thus unsurprising that each analysis is also ex post in operational terms. GIL's key explanatory variable postdates the phenomenon they seek to explain, while Swank's key explanatory variable is simply a recoded version of his dependent variable.

Both analyses exhibit a second general difficulty, although it is displayed more directly by Swank. The ecumenical effort to find a middle ground between institutional and cultural explanations is not apt to prove fruitful, because the two are incompatible. We are hardly the first to note the problem. In an insightful evaluation of revisionists, like Tawney (1926), who sought to modify the Weber thesis, Samuelsson pointed out that:

Such writers, disposed to compromise, evidently believe that false concepts can be made into perfectly sensible ones simply by taking little bits of each an glueing them together into a "between-the-two" or "as-well-as" joinery of totally opposed notions $(1961,25)$.

Weber, of course, fundamentally treated values as exogenous, and this is the distinctive element of the "value enactment" approach (Portes 1976). Analyses like Putnam's, Inglehart's, and Swank's follow very much in the same tradition. In sharp contrast, the institutional approach endogenizes values (e.g., Hirschman 1984; Knight 1992; Gambetta 1993). Because it makes no sense to think of values as being half exogenous, this difference cannot be split.

We could, of course, continue to draw rabbits from the cultural hat. 
The more fruitful strategy, however, involves institutional analyses that address two basic questions. First, how do procedures and rules structure the choices made by different political actors? Second, how does political conflict generate these procedures and rules? The analyses in this symposium have given us no reason to depart from these fundamental political issues.

Final manuscript received 1 December 1995.

\section{APPENDIX \\ Survey Question from which "Achievement Orientations" are Generated}

Here is a list of qualities which children can be encouraged to learn at home. Which, if any, do you consider to be especially important? Please choose up to five. (CODE FIVE ONLY)
A) Good manners
B) Independence
C) Hard work
D) Feeling of responsibility
E) Imagination
F) Tolerance and respect for other people
G) Thrift, saving money and things
H) Determination, perseverance
I) Religious faith
J) Unselfishness
K) Obedience

Italicized items included in GIL's (1996) index of achievement motivation.

Source: World Values Survey, 1990 (ICPSR study \# 6160), variables \#226-\#236.

\section{REFERENCES}

Abramson, Paul R., and Ronald Inglehart. 1995. Value Change in Global Perspective. Ann Arbor: University of Michigan Press.

Ajayi, J. F. Ade. 1965. Christian Missions in Nigeria: The Making of a New Elite. Evanston, IL: Northwestern University Press.

Barro, Robert J. 1991. "Economic Growth in a Cross Section of Countries." Quarterly Journal of Economics 106:407-44.

Barrow, Julia. 1990. "German Cathedrals and the Monetary Economy in the Twelfth Century." Journal of Medieval History 16:13-38. 
Beck, Nathaniel, and Jonathan N. Katz. 1995. "What To Do (and Not to Do) with TimeSeries-Cross-Section Data in Comparative Politics." American Political Science Review 89:634-47.

Billig, Michael S. 1994. "The Death and Rebirth of Entrepreneurism on Negros Island, Philippines: A Critique of Cultural Theories of Enterprise." Journal of Economic Issues 28:659-78.

Bossy, John. 1985. Christianity in the West: 1400-1700. New York: Oxford University Press.

Bridbury, A. R. 1992. The English Economy from Bede to the Reformation. Rochester, NY: Boydell Press.

Britnell, Richard H. 1993a. " Commerce and Capitalism in Late Medieval England: Problems of Description and Theory." Journal of Historical Sociology 6:359-76.

Britnell, Richard H. 1993b. The Commercialisation of English Society, 1000-1500. New York: Cambridge University Press.

Britnell, Richard H., and Bruce M. S. Campbell, eds. 1995. A Commercialising Economy: England 1086 to c. 1300. Manchester: Manchester University Press.

Carus-Wilson, E. M. 1967. Medieval Merchant Venturers: Collected Studies. London: Methuen.

Cipolla, Carlo M. 1980. Before the Industrial Revolution: European Society and Economy, 1000-1700. New York: Norton.

Clarke, Harold D., and Nitish Dutt. 1991. "Measuring Value Change in Western Industrialized Societies: The Impact of Unemployment." American Political Science Review 85: 905-20.

Clarke, Harold D., Nitish Dutt, and Allan Kornberg. 1993. "The Political Economy of Attitudes Toward Polity and Society in Western European Democracies." Journal of Politics 55:998-1021.

Cohen, Jere. 1980. "Rational Capitalism in Renaissance Italy." American Journal of Sociology 85:1340-55.

Day, John. 1987. The Medieval Market Economy. New York: Blackwell.

de Roover, Raymond. 1963. The Rise and Decline of the Medici Bank 1397-1494. Cambridge: Harvard University Press.

de Roover, Raymond. 1974. Business, Banking, and Economic Thought in Late Medieval and Early Modern Europe. Chicago: University of Chicago Press.

Duch, Raymond M., and Michaell A. Taylor. 1993. "Postmaterialism and the Economic Condition." American Journal of Political Science 37:747-79.

Du Plessis, Johannes. 1911. A History of Christian Missions in South Africa. London: Longmans Green.

Duvall, Louis M. 1928. Baptist Missions in Nigeria. Richmond, VA: Southern Baptist Convention.

Epstein, Steven A. 1991. Wage Labor and Guilds in Medieval Europe. Chapel Hill: University of North Carolina Press.

Festinger, Leon. 1957. A Theory of Cognitive Dissonance. Stanford: Stanford University Press.

Fukuyama, Francis. 1995. Trust: The Social Virtues and the Creation of Prosperity. New York: Free Press.

Gambetta, Diego. 1993. The Sicilian Mafia: The Business of Private Protection. Cambridge: Harvard University Press.

Geddes, Barbara. 1990. "How the Cases You Choose Affect the Answers You Get: Selection Bias in Comparative Politics." Political Analysis 2:131-50. 
Gies, Frances, and Joseph Gies. 1994. Cathedral, Forge, and Waterwheel: Technology and Invention in the Middle Ages. New York: Harper-Collins.

Gies, Joseph, and Frances Gies. 1972. Merchants and Moneymen: The Commercial Revolution, 1000-1500. New York: Crowell.

Gilchrist, J. 1969. The Church and Economic Activity in the Middle Ages. New York: St. Martin's.

Granato, Jim, Ronald Inglehart, and David Leblang. 1996. "The Effect of Cultural Values on Economic Development: Theory, Hypotheses, and Some Empirical Tests." American Journal of Political Science 40:607-31.

Hatcher, John. 1986. "Mortality in the Fifteenth Century: Some New Evidence." Economic History Review 39:19-38.

Hatcher, John. 1994. "England in the Aftermath of the Black Death." Past and Present 144:3-35.

Helliwell, John F. 1994. "Empirical Linkages Between Democracy and Growth.” British Journal of Political Science 24:225-48.

Hicks, Alexander. 1988. "Social Democratic Corporatism and Economic Growth.” Journal of Politics 50:677-704.

Hirschman, Albert O. 1984. “A Dissenter's Confession: 'The Strategy of Economic Development' Revisited." In Pioneers in Development, ed. Gerald M. Meier and Dudley Seers. New York: Oxford University Press.

Hunt, Edwin S. 1994. The Medieval Super-Companies: A Study of the Peruzzi Family of Florence. New York: Cambridge University Press.

Inglehart, Ronald. 1990. Culture Shift in Advanced Industrial Society. Princeton: Princeton University Press.

Jackman, Robert W. 1987. "The Politics of Economic Growth in the Industrial Democracies, 1974-80: Leftist Strength or North Sea Oil?' Journal of Politics 49:242-56.

Jackman, Robert W. 1989. "The Politics of Economic Growth, Once Again." Journal of Politics 51:152-67.

Jackman, Robert W., and Ross A. Miller. 1996. “A Renaissance of Political Culture?” American Journal of Political Science 40:632-59.

Kahn, Herman. 1979. World Economic Development: 1979 and Beyond. Boulder, CO: Westview.

Knight, Jack. 1992. Institutions and Social Conflict. New York: Cambridge University Press.

Lange, Peter, and Geoffrey Garrett. 1985. "The Politics of Growth: Strategic Interaction and Economic Performance in the Advanced Industrial Democracies." Journal of Politics 47:792-827.

Lehmann, Hartmut, and Guenther Roth, eds. 1993. Weber's Protestant Ethic: Origins, Evidence, Contexts. New York: Cambridge University Press.

Levine, Ross, and David Renelt. 1992. "A Sensitivity Analysis of Cross-Country Growth Regressions." American Economic Review 82:942-63.

Lopez, Robert S. 1976. The Commercial Revolution of the Middle Ages, 950-1350. New York: Cambridge University Press.

MacKinnon, Malcolm H. 1988. "Part I: Calvinism and the Infallible Assurance of Grace: The Weber Thesis Reconsidered," and "Part II: Weber's Exploration of Calvinism: The Undiscovered Provenance of Capitalism." British Journal of Sociology 39:143210 .

MacKinnon, Malcolm H. 1994. "Believer Selectivity in Calvin and Calvinism." British Journal of Sociology 45:585-95.

McClelland, David C. 1961. The Achieving Society. Princeton: D. Van Nostrand Co. 
McClelland, David C. 1963. "National Character and Economic Growth in Turkey and Iran." In Communications and Political Development, ed. Lucian W. Pye. Princeton: Princeton University Press.

McClelland, David C., and David G. Winter. 1969. Motivating Economic Achievement. New York: Free Press.

McNeill, William H. 1977. Plagues and Peoples. New York: Anchor Books.

Messmore, J. H. 1903. The Life of Edwin Wallace Parker, D.D., Missionary Bishop of Southern Asia, Forty-one Years a Missionary in India. New York: Eaton and Mains.

Miller, Edward, and John Hatcher. 1995. Medieval England: Towns, Commerce and Crafts, 1086-1348. New York: Longman.

Mitchell, J. Murray. 1899. In Western India: Recollections of My Early Missionary Life. Edinburgh, Scotland: D. Douglas.

Outhwaite, R. B. 1986. "Progress and Backwardness in English Agriculture, 1500-1650." Economic History Review 39:1-18.

Persson, Karl Gunnar. 1988. Pre-Industrial Economic Growth: Social Organization and Technological Progress in Europe. New York: Blackwell.

Portes, Alejandro. 1976. "On the Sociology of National Development: Theories and Issues." American Journal of Sociology 82:55-85.

Putnam, Robert D. 1993. Making Democracy Work: Civic Traditions in Modern Italy. Princeton: Princeton University Press.

Pye, Lucian W. 1985. Asian Power and Politics: The Cultural Dimensions of Authority. Cambridge: Harvard University Press.

Pye, Lucian W. 1991. China: An Introduction. 4th ed. New York: HarperCollins.

Reynolds, Robert L. 1961. Europe Emerges: Transition Toward an Industrial World-Wide Society 600-1750. Madison: University of Wisconsin Press.

Ross, Andrew. 1986. John Philip, 1775-1851: Missions, Race, and Politics in South Africa. Aberdeen, Scotland: Aberdeen University Press.

Samuelsson, Kurt. 1961. Religion and Economic Action. London: Heinemann.

Stewart, Robert. 1899. Life and Work in India: An Account of the Conditions, Methods, Difficulties, Results, Future Prospects and Reflex Influence of Missionary Labor in India. Philadelphia: Pearl Publishing.

Swank, Duane. 1992. "Politics and the Structural Dependence of the State in Democratic Capitalist Nations." American Political Science Review 86:38-54.

Swank, Duane. 1996. "Culture, Institutions, and Economic Growth." American Journal of Political Science 40:660-79.

Tawney, Richard H. 1926. Religion and the Rise of Capitalism. New York: Harcourt Brace.

Titow, Jan. 1994. "Lost Rents, Vacant Holdings and the Contraction of Peasant Holdings After the Black Death." Agricultural History Review 42:97-114.

Trevor-Roper, Hugh R. 1972. Religion, the Reformation and Social Change. London: Macmillan.

Weber, Max. 1951. The Religion of China: Confucianism and Taoism. New York: Free Press.

Weber, Max. 1958. The Protestant Ethic and the Spirit of Capitalism. New York: Scribner's.

White, Lynn, Jr. 1978. Medieval Religion and Technology. Berkeley and Los Angeles: University of California Press.

Wright, A. D. 1982. The Counter-Reformation: Catholic Europe and the Non-Christian World. London: Weidenfeld and Nicolson. 